\title{
An unmet clinical need: roads to remyelination in MS
}

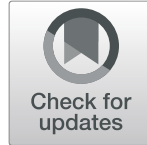

\author{
Peter Göttle ${ }^{1}$, Moritz Förster ${ }^{1}$, Vivien Weyers ${ }^{1}$, Patrick Küry ${ }^{1}$, Konrad Rejdak², Hans-Peter Hartung ${ }^{1}$ and \\ David Kremer ${ }^{1 *}$
}

\begin{abstract}
Background: In the central nervous system (CNS) myelin sheaths stabilize, protect, and electrically insulate axons. However, in demyelinating autoimmune CNS diseases such as multiple sclerosis (MS) these sheaths are destroyed which ultimately leads to neurodegeneration. The currently available immunomodulatory drugs for MS effectively control the (auto)inflammatory facets of the disease but are unable to regenerate myelin by stimulating remyelination via oligodendroglial precursor cells (OPCs). Accordingly, there is broad consensus that the implementation of new regenerative approaches constitutes the prime goal for future MS pharmacotherapy.

Main text: Of note, recent years have seen several promising clinical studies investigating the potential of substances and monoclonal antibodies such as, for instance, clemastine, opicinumab, biotin, simvastatin, quetiapin and anti-GNbAC1. However, beyond these agents which have often been re-purposed from other medical indications there is a multitude of further molecules influencing OPC homeostasis. Here, we therefore discuss these possibly beneficial regulators of OPC differentiation and assess their potential as new pharmacological targets for myelin repair in MS.

Conclusion: Remyelination remains the most important therapeutic treatment goal in MS in order to improve clinical deficits and to avert neurodegeneration. The promising molecules presented in this review have the potential to promote remyelination and therefore warrant further translational and clinical research.
\end{abstract}

Keywords: Remyelination, Myelin, Neurodegeneration, Oligodendrocyte, Therapy, Multiple sclerosis

\section{Introduction}

Axonal myelin sheaths enable saltatory signal transduction which accelerates information processing 20-100-fold. However, many diseases of the central nervous system (CNS) such as multiple sclerosis (MS) harm or destroy myelin sheaths and the myelin-producing oligodendrocytes resulting in demyelination. MS is an autoimmune inflammatory CNS disease of yet unclear etiology [75, 91]. Its most common clinical course is the relapsing subtype (RMS) which can manifest itself in a plethora of acute clinical symptoms (i.e. relapses) ranging from paresthesias to ataxia or even motor weakness. Most RMS cases ultimately transform into (secondary) progressive MS (PMS) where neurodegeneration outweighs inflammation. Even though there is evidence that adult oligodendrocyte can contribute to myelin repair in the adult CNS $[18,103]$,

\footnotetext{
* Correspondence: david.kremer@med.uni-duesseldorf.de

1 Department of Neurology, Medical Faculty, Heinrich-Heine-University,

Moorenstrasse 5, 40225 Düsseldorf, Germany

Full list of author information is available at the end of the article
}

remyelination is thought to be mostly mediated by an ubiquitous pool of so-called oligodendroglial precursor cells (OPCs) which can differentiate into mature cells and then generate new myelin [10]. Unfortunately, this spontaneously occurring process called remyelination is overall inefficient and results in shorter and thinner myelin sheaths. Neuropathologically, this is mirrored by the presence of so-called shadow plaques - lightly remyelinated lesions with intermediate levels of myelin. Critical steps for remyelination such as OPC activation, recruitment, differentiation, and ultimately myelin regeneration are orchestrated by a number of extrinsic and intrinsic factors that act either as inhibitors or stimulators of OPC differentiation $[47,50]$. Of note, recent publications point to an increasing heterogeneity within the oligodendroglial lineage reflecting differences between white and grey matter localisation and origin [94], different CNS regions [59] as well as lineage alterations upon demyelination [20, 40]. Moreover, as mentioned above, in the diseased adult CNS an additional contribution to myelin repair from partially 
lesioned oligodendrocytes has recently been suggested $[18,103]$. Lastly, the subventricular zone (SVZ) stem cell niche represents yet another source for adult oligodendrogenesis, which is therefore contributing to glial heterogeneity [2]. This review will discuss recently identified molecules affecting OPC differentiation which may represent new therapeutic strategies to exogenously promote remyelination in MS (see Table 1 and Fig. 1 for a respective overview).

\section{Receptors/membrane-bound molecules Klotho}

As a single-pass transmembrane protein, Klotho is primarily found in the kidney and the CNS [52]. As a result of ectodomain shedding, cleaved Klotho can act as a ligand, hormone and/or glycosidase regulating ion homeostasis. Furthermore, it modulates the Wnt and insulin/ IGF1 pathways which represses IGF-1 signaling [51]. Recent studies found that Klotho accelerates remyelination in cuprizone-mediated demyelination animal models [92]. In this context, it is important to note that by means of a knock-out animal model Klotho had previously already been shown to promote OPC maturation via the phosphorylation of FRS2, ERK and Akt leading to an activation of mammalian target of rapamycin (mTOR; [12]). However, given its inability to cross the blood-brain barrier (BBB), a small molecule approach aimed at increasing endogenous Klotho production appears to be the most promising therapeutic strategy [1]. Moreover, the uncleaved Klotho transmembrane protein acts as a co-receptor forming a complex with fibroblast growth factor receptor (FGFR) responsible for FGF23 signaling which is involved in vitamin D production [72, 73]. Regarding other members of the FGF family, $\beta$-klotho was demonstrated to enhance remyelination in a toxic demyelination animal model based on an interaction with FGF21. This effect seems to result from a stimulation of OPC proliferation promoting CNS regeneration [53].

\section{Smoothened (Smo)}

Besides the already mentioned Wnt, insulin/IGF and FGF signaling pathways, sonic hedgehog (Shh) signaling seems to play an important role in OPC differentiation. Inhibition of the atypical $\mathrm{G}$ protein-coupled receptor Smoothened (Smo), an activator of Shh signaling, caused a dramatic decrease in myelin marker expression such as myelin basic protein (MBP) and myelin associated glycoprotein (MAG) during OPC differentiation in cell culture [95]. As a result, Smo constitutes a potential therapeutic target for myelin repair [14]. In vitro cell culture-based drug screening approaches and functional remyelination studies (both in ex vivo cerebellar cultures and a neuromyelitis optica animal model) identified a number of active compounds with remyelination/myelin repair properties that act as Smo agonists, such as, for instance, clobetasol which is a corticosteroid already approved for the treatment of skin diseases such as psoriasis (CLOB; $[65,71,102])$.

\section{Myelin regulatory factor (MYRF)}

Myelin regulatory factor (MYRF) is a membrane-bound transcription factor tightly associated with the endoplasmic reticulum (ER; $[19,34])$. As revealed by MRF conditional knockout (CKO) mice, upon self-cleavage, the $\mathrm{N}$ terminal fragment of MYRF translocates from the ER into the nucleus where it functions as a transcription factor stimulating myelin gene promotor activity [19]. Hence, it seems to be critical for oligodendroglial differentiation and myelin maintenance [46]. Studies in lysolecithin-induced demyelination animal models point to an essential role of MYRF in remyelination/myelin repair which is underlined by the observation that in chronic human MS lesions oligodendrocytes were found to lack MYRF expression [17].

\section{Repulsive guidance molecule a (RGMa)}

Repulsive guidance molecules (RGMs) are a small family of membrane-bound proteins with tissue-specific expression which were initially described as axonal guiding factors during embryogenesis. However, recently they were also recognized as being involved in multiple cellular processes such as axon guidance during adulthood, neuronal survival, axonal regeneration, iron metabolism and skeletal development [83]. As a member of this family, RGMa was identified as a regulatory factor potentially facilitating inflammation and inhibiting regeneration and remyelination in MS [15]. RGMa acts mainly through its target receptor neogenin which it activates differently depending on its previous proteolytic processing: either involving activation of LARG, RhoA, and ROCK or via $\gamma$-secretase cleavage of the intracellular domain of neogenin [4]. In CD4+ T cells, RGMa leads to an activation of the GTPase Rap1 resulting in an increased adhesion of $T$ cells to intracellular adhesion molecule-1 (ICAM-1; [63]). However, although not directly inhibiting $\mathrm{T}$ cell trafficking to the CNS, the use of murine EAE (experimental autoimmune encephalomyelitis) animal models demonstrated that treatment with anti-RGMa antibodies resulted in a diminished $\mathrm{T}$ cell proliferation as well as inflammation as indicated by a reduced IL-2, IL-4, IFN- $\gamma$ and IL-17 secretion. Accordingly, the clinical course of EAE was improved as compared to controls [63]. Of note, this beneficial therapeutic effect was also confirmed in an SPMS animal model, where anti-RGMa antibody treatment prevented secondary progression of EAE, inhibited inflammation and promoted neuroregeneration in the murine spinal cord leading to functional recovery [89]. In addition, this study showed that anti-RGMa antibody treatment reduced 


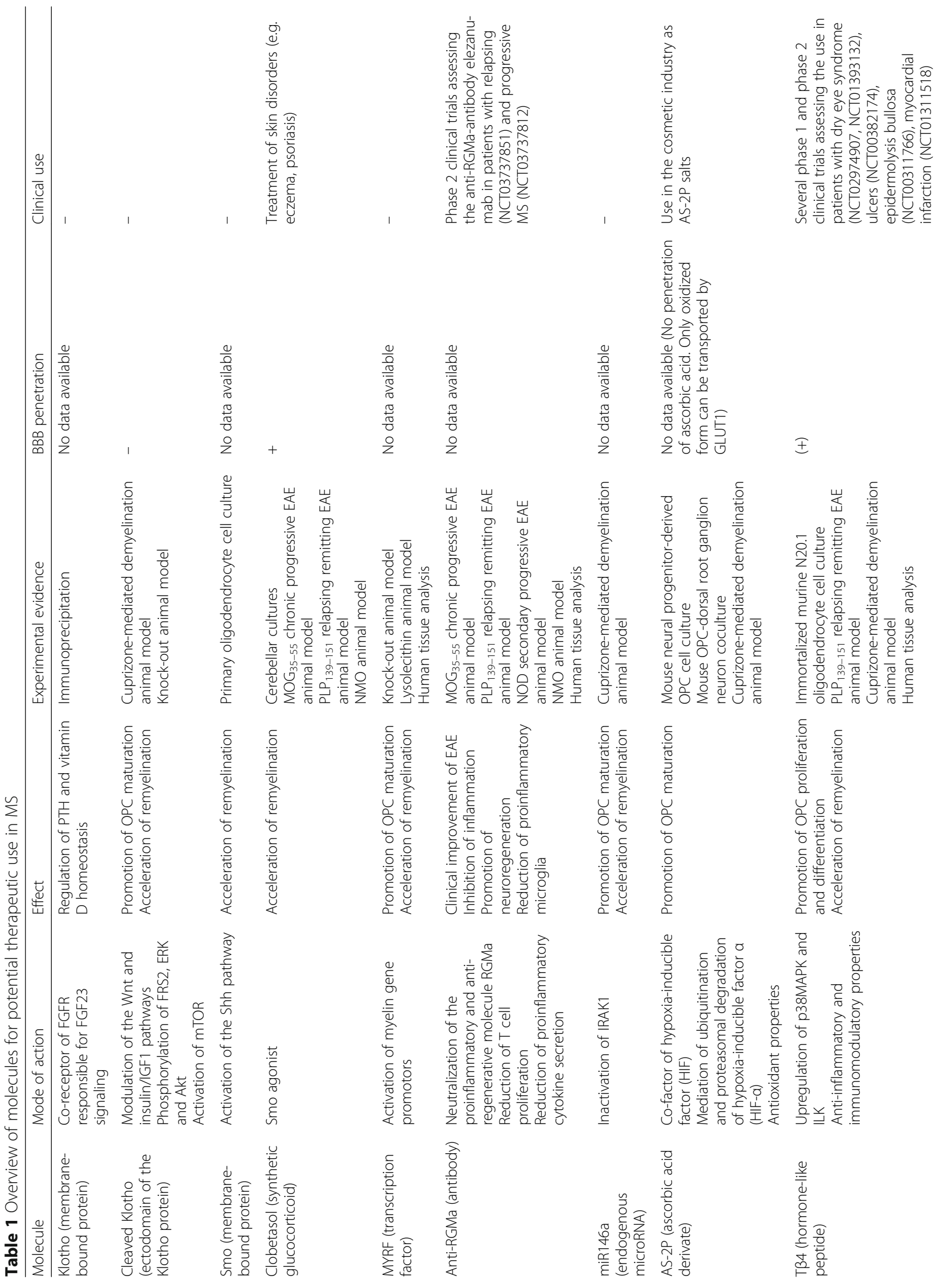




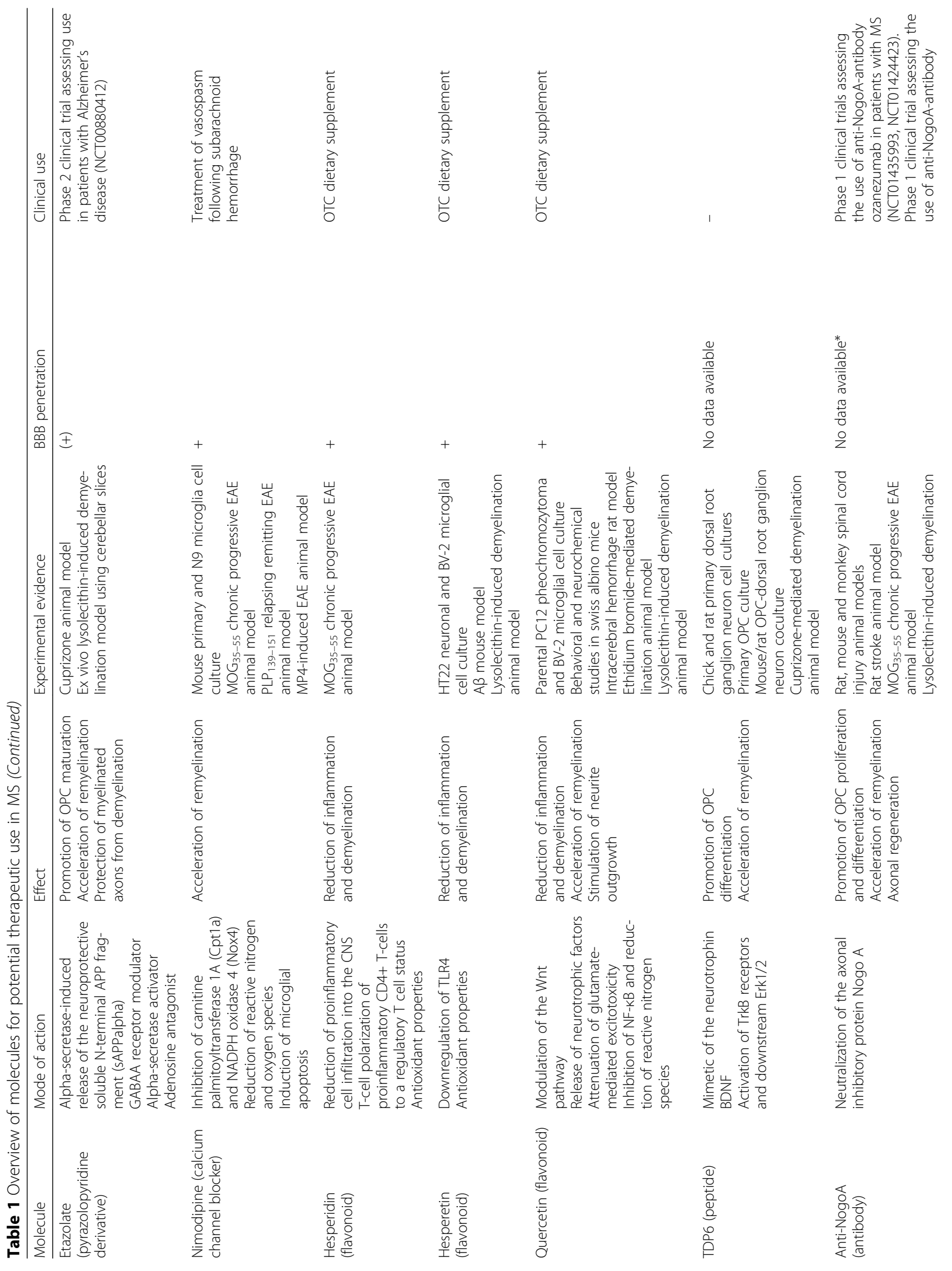




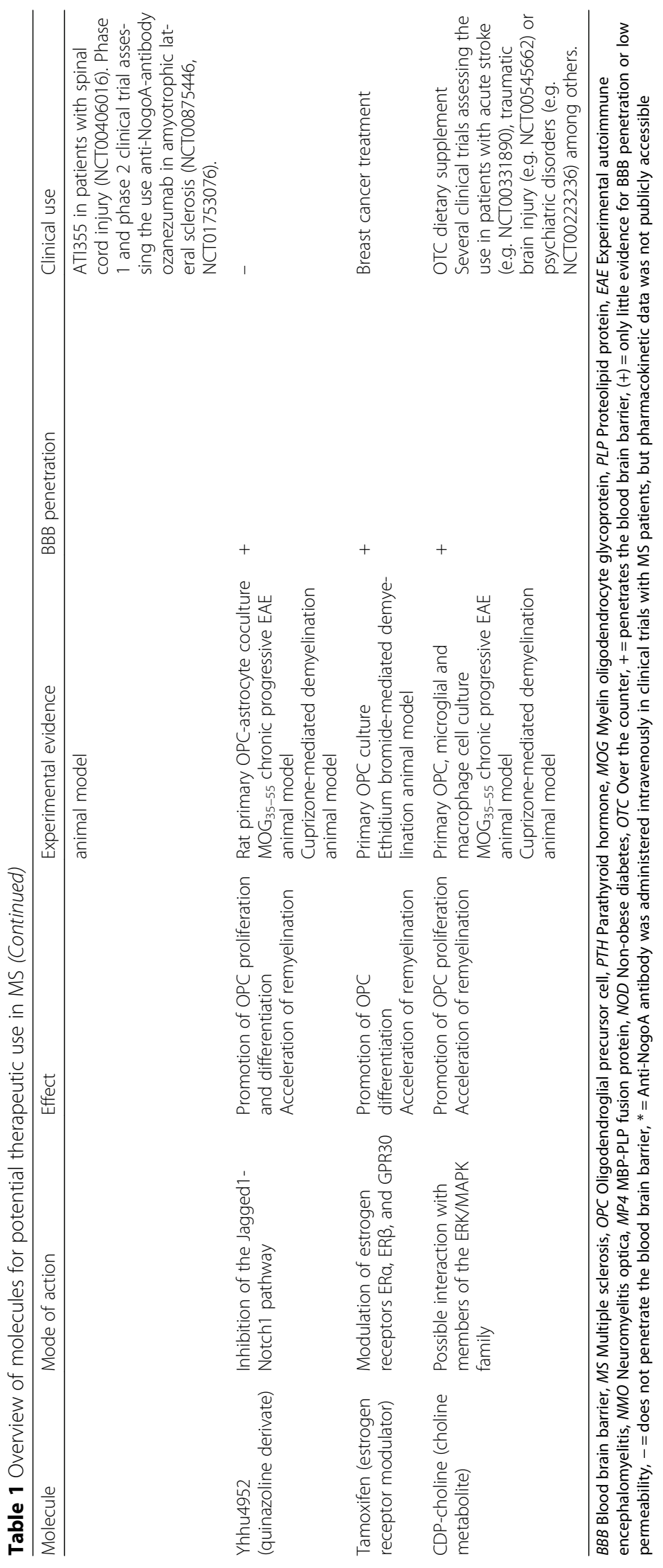




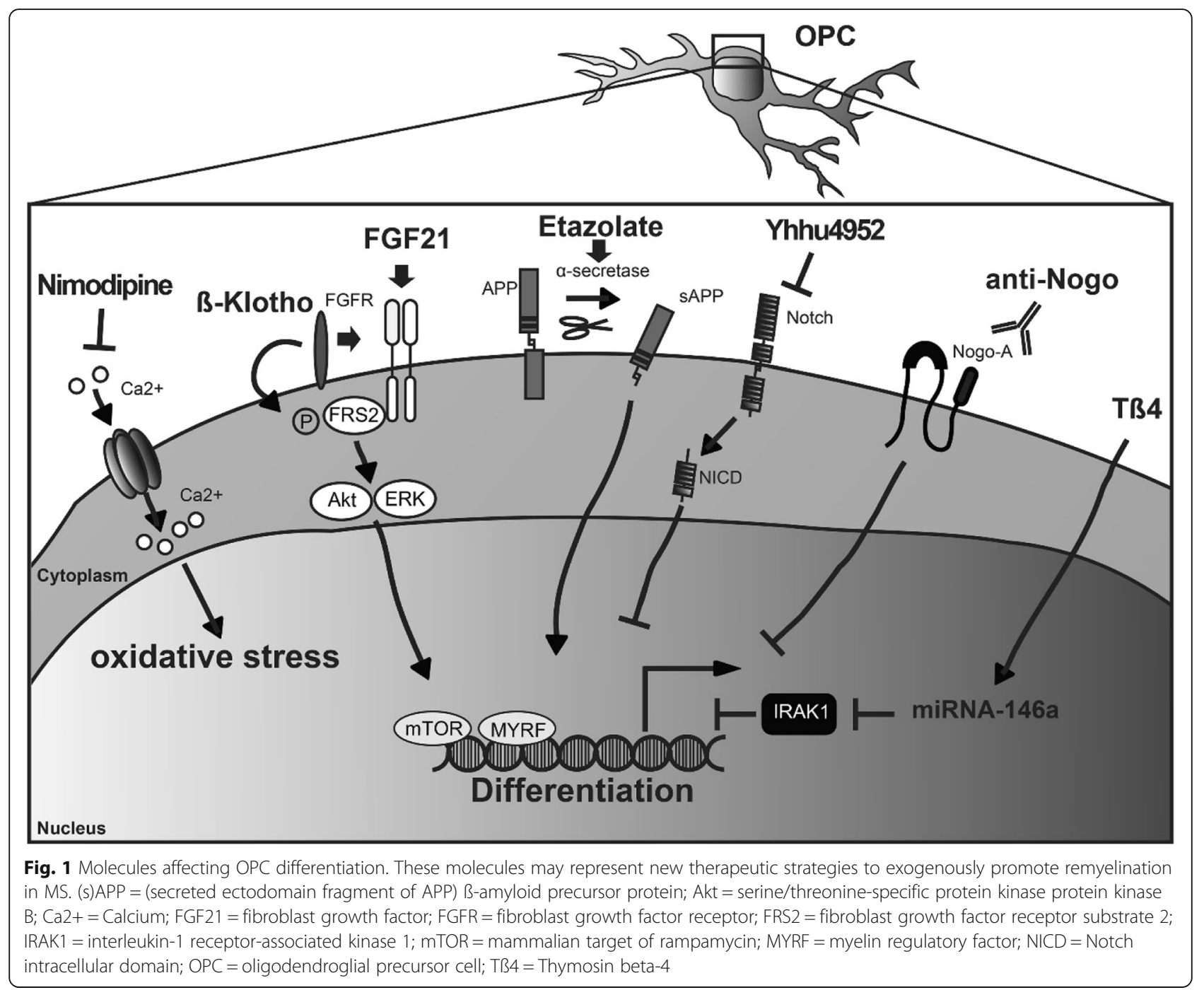

the number and activation of CD11b + microglia in the inflamed CNS. Interestingly, activated microglia were also shown to express RGMa and to inhibit axonal outgrowth via direct cell to cell contact. This effect could be reversed not only by the anti-RGMa antibody but also by the antibiotic minocycline recently tested in clinical trials as a potential treatment option for clinically isolated syndrome (CIS) [45, 61]. In addition, RGMa may also be involved in neuromyelitis optica (NMO) as in an NMO animal model similar effects of anti-RGMa treatment were observed such as a more favourable disease course, a weaker immune response, and a partial restoration of AQP4 and GFAP reactivity [33].

\section{Physiologically occurring free molecules}

miR-146a

During the past years, microRNAs and their dysregulated expression have been studied extensively in MS pathology [16]. Pharmaceutically, they are of interest due to the idea that they could be delivered to target structures via extracellular vesicles [69]. MicroRNA miR-146a was assigned a potential role in myelin repair as it was demonstrated to promote oligodendroglial differentiation and to enhance remyelination in the toxically demyelinated corpus callosum of mice [108]. Mechanistically, it is thought to inactivate interleukin-1 receptor-associated kinase 1 (IRAK1), an intracellular signaling molecule disturbing OPC differentiation [48].

\section{L-ascorbyl-2-phosphate (AS-2P)}

Various studies have demonstrated decreased levels of ascorbic acid in the serum of MS patients [7, 90]. In this context, in vitro and in vivo experiments recently identified L-ascorbyl-2-phosphate (AS-2P), a stable form of vitamin $\mathrm{C}$, to be able to stimulate OPC differentiation into mature and myelinating oligodendrocytes [31]. AS2P was found to increase the expression of oligodendroglial myelin markers such as $2^{\prime}, 3^{\prime}$-Cyclic-nucleotide $3^{\prime}$ - 
phosphodiesterase (CNPase) and MBP and to facilitate the formation of myelin sheaths in $\mathrm{OPC} /$ neuron cocultures. In addition, As-2P also exerts a regenerative impact in the toxic cuprizone animal model. Interestingly and of note, all these effects seem to be independent of its well-described antioxidant properties.

\section{Thymosin- $\beta 4$}

Thymosin beta- 4 (timbetasin, $\mathrm{T} \beta 4$ ) is a 43 -amino acid hormone-like peptide which is mainly involved in the regulation of cell motility and migration. It is thought to interact with globular actin (G-actin) regulating actin polymerization and ultimately microfilament formation [78]. Furthermore, recent studies demonstrated T $\beta 4$ to have anti-inflammatory and immunomodulatory properties, to promote OPC proliferation and differentiation as well as remyelination in the CNS. In EAE and the cuprizone model, T $\beta 4$ treatment led to a significant neurological functional improvement which was accompanied by a reduction of inflammatory cell infiltrates, an enhanced oligodendrogenesis and recruitment of OPCs to demyelinated axons which resulted in a relevant reduction of axonal damage in the demyelinating CNS [107, 109]. In MS brains, it was found to be present in the periphery of not yet fully remyelinated lesions which, in the context of the previous findings, suggests a restorative effect [57]. On the other hand, proteomic profiling studies of cerebrospinal fluid (CSF) showed significantly decreased T $\beta 4$ levels in MS patients as compared to patients with other neurological diseases [55]. Mechanistically, the exact mode of action of $\mathrm{T} \beta 4$ still needs further clarification but seems to be multifaceted as $\mathrm{T} \beta 4$ has several biological functions [25]. However, $\mathrm{T} \beta 4$ leads to an upregulation of p38 mitogen-activated protein kinase (p38MAPK; [79]), miRNA 146a [80, 108, 111], and smoothened-activating integrin linked kinase (ILK) [44], all of them being involved in the mediation of OPC differentiation (see further above).

\section{Non-physiologically occurring free molecules Etazolate}

The pyrazolopyrine derivate etazolate features unique pharmacological properties as it simultaneously acts as an alpha-secretase activator, an allosteric GABAA receptor modulator [58], an adenosine antagonist [97] and a phosphodiesterase (PDE) inhibitor for PDE4 [96]. In demyelinating animal models etazolate has been shown to promote the restoration of myelinated axons via an alphasecretase-induced release of the soluble N-terminal APP fragment (sAPPalpha), an endogenous protein with neuroprotective properties [56]. Of note, a clinical trial in Alzheimer's disease (AD) already demonstrated a favorable clinical safety/tolerability profile (ClinicalTrials.gov Identifier: NCT00880412).

\section{Nimodipine}

The voltage gated L-type calcium channel blocker nimodipine is commonly used clinically to prevent cerebral vasospams often following subarachnoid haemorrhage $(\mathrm{SAH})$. In different EAE animal models and in cell culture experiments nimodipine was demonstrated to exert a positive impact on both inflammation and neurodegeneration via the induction of microglial apoptosis and improved oligodendrogenesis [81]. Of note, it does so without affecting the primary immune response. As it exerts a protective effect on neurons and is able to preserve myelin in EAE, nimodipine seems to be a promising candidate for both RMS and PMS [39].

\section{Hesperidin and hesperetin}

Hesperidin is a common flavanone from the fruit peel of Citrus aurantium (bitter orange) with antioxidant, anti-inflammatory and neuroprotective properties [77]. Oxidative stress is assumed to be one of the causes of neurodegeneration in MS [26] so that antioxidant compounds have long been regarded as a protective therapy option [27, 35, 84]. In MOG-induced EAE hesperidin treatment led to a reduction of disease severity. This effect is probably mediated by a hesperidin-induced reduction of proinflammatory cell infiltration into the CNS, a T-cell polarization of proinflammatory CD4+ Tcells to a regulatory $\mathrm{T}$ cell status and a subsequent shift from proinflammatory IL-1b, IL-6, IL-17, and TNF- $\alpha$ to regulatory $\mathrm{L}-10$ and TGF- $\beta$ cytokines $[13,32]$. In addition, the aglycone derivate of hesperidin (hesperetin) inhibits neuroinflammation by a downregulation of TLR4 which leads to a decrease of the proinflammatory TLR4-dependent downstream cytokines NF- $\mathrm{B}, \mathrm{TNF}-\alpha$, and IL-1 $\beta$ as demonstrated in an $A \beta$ mouse model [36]. The administration of hesperetin in a lysolecithin (LPC)-induced focal demyelination animal model demonstrated a decreased demyelination and glial activation in the optic chiasm which led to a functional recovery and might reflect a beneficial impact of hesperetin on remyelination [5].

\section{Quercetin}

Like hesperidin, the flavonol quercetin is a member of the flavonoid group and thus considered to possess antioxidant, antiviral and neuroprotective properties. Its neuroprotective effect is mainly based on its anti-inflammatory and antioxidant activity as well as its ability to induce the release of neurotrophic factors while simultaneously attenuating glutamate-mediated excitotoxicity [88]. Quercetin treatment was shown to reduce the expression levels of the proinflammatory cytokines TNF- $\alpha$, IL-6, IL-1 $\beta$ and COX-2 
[60] promoting a functional recovery in the inflamed CNS based on an animal model of intracerebral hemorrhage [110]. Cell culture experiments revealed that quercetin enhances neurite outgrowth by the release of neurotrophic factors, such as brain-derived neurotrophic factor (BDNF), neurotrophin (NGF; [66]), growth-associated protein 43 (GAP43) and microtubule-associated protein (MAP; [62]). Furthermore, it can potentially decrease nitrosative stress by inhibiting NF- $\mathrm{kB}$ and its downstream effector inducible nitric oxide synthase (iNOS; [43]). Regarding remyelination, recent studies demonstrated that quercetin interferes with the canonical Wnt signaling pathway by separating the Wnt-downstream transcription regulating protein $\beta$ catenin from transcription factor 4 [21, 22, 104], which in turn improves myelin repair as demonstrated in demyelinating animal models $[8,64]$.

\section{Tricyclic dimeric peptide 6 (TDP6) - BDNF}

Tricyclic dimeric peptide 6 (TDP6) is a small multicyclic peptide that mimics a distinct region of the neurotrophin BDNF which exerts its effect via the transmembrane tropomyosin-related kinase $\mathrm{B}$ (TrkB) receptor [11]. BDNF is required for normal CNS myelination [9, 41] and is able to directly enhance myelination in oligodendrocytes [100]. Cell culture studies demonstrated, that TDP6 selectively targets TrkB receptors [67] and activates the downstream signaling molecules extracellular related-kinase 1 and 2 (Erk1/2; [98]) which in turn promotes remyelination $[24,99]$. Further studies in EAE demonstrated that stimulation of TrkB enhances remyelination by increasing oligodendrocyte differentiation, the frequency of myelinated axons and myelin sheath thickness [23].

\section{Miscellaneous other molecules}

Anti-NogoA antibodies were previously developed for and intensively studied in axonal regeneration of the acutely injured CNS [82]. Their application in a rodent lysolecithin-based demyelinating animal model was found to promote remyelination of axon tracts in the spinal cord [37]. This indicates that anti-NogoA treatment might constitute a potential anti-degenerative approach particularly interesting regarding PMS in which axonal degeneration is thought to outweigh inflammation [38]. Aside from that, Notch signaling has been found to play an important role in the regulation of developmental and repair-associated oligodendrogenesis [42]. Interestingly, it was now shown that the small molecule Yhhu4952 can be used to inhibit the Jagged1-Notch1 pathway and when applied to cuprizone-demyelinated or EAE animal models it was found to boost oligodendroglial differentiation and to improve myelin restoration [106]. Besides these factors tamoxifen, an FDA-approved selective estrogen receptor modulator (SERM) used for the treatment of breast cancer, was found to induce OPC differentiation in culture and to accelerate remyelination in demyelinating animal models [28]. Further studies demonstrated that modulation of estrogen receptors ER $\alpha$, ER $\beta$, and GPR30 are responsible for the observed effects [6]. Another interesting approach is to use choline metabolites such as CDP-choline (citicoline) to enhance remyelination in MS [29, 30, 76, 85]. CDPcholine was found to ameliorate the disease course of EAE and to exert beneficial effects on myelin, oligodendrocytes and axons. Upon cuprizone-induced demyelination, CDP-choline stimulated myelin regeneration and reversed motor coordination deficits. Mechanistically, increased remyelination apparently arises from an increase in the numbers of proliferating OPCs and oligodendrocytes [86].

\section{Conclusion}

Remyelination remains the most important therapeutic treatment goal in MS in order to improve clinical deficits and to avert neurodegeneration which is already present at early stages of the disease [49]. This is of particular importance as neurodegeneration dictates in large measure the accumulating neurological disability in MS. Even in radiologically isolated syndrome (RIS), a controversially discussed precursor to MS based exclusively on the incidental finding of clinically asymptomatic MRI lesions, there is evidence for thalamic volume loss as a correlate of early neurodegeneration [3]. It is therefore very encouraging to observe the plethora of emerging clinical studies investigating the potential of different agents to promote remyelination. Once fully established, such therapies will probably be used as add-on medications in a two-pronged approach alongside "classical "immunomodulators. Of course, translation of experimental findings into clinical trials assessing remyelination faces significant challenges. Notably it is unclear which outcome measures should be best used in order to adequately monitor therapeutic efficiency [68, 87]. Secondly, molecules supposed to stimulate OPC differentiation should not exert negative pleiotropic effects on otherwise physiologically required homeostatic pathways. This is particularly true for experimental molecules aiming at a modulation of the activity of receptors and membrane-bound proteins such as, for instance, Klotho, Wnt, Smo and RGMa. Accordingly, for entirely new molecules extensive animal studies will be an absolute prerequisite as a first line of verification that they are well-tolerated and do not lead to serious adverse events (SAEs). In contrast, repurposing of well-known drugs already approved for other medical indications constitutes an elegant strategy to avoid SAEs, to accelerate clinical development and to secure patient trust. Of note, in order to produce effects on remyelination potential molecules need to be able to cross the $\mathrm{BBB}$ into the brain. It is therefore key to find effective 
ways of delivery, all the more, as it is a misconception that even most so-called small molecules (i.e. <900 Da) can easily cross the BBB [70]. At least for Clobetasol [65], Yhhu4952 [106], tamoxifen [54], nimodipine [93], CDPcholine [74] and the flavonoids [101, 105] BBB penetration has already been established (see Table 1). Despite all these challenges, looking at the multitude of promising molecules presented in this review is extremely reassuring.

\begin{abstract}
Abbreviations
AD: Alzheimer's disease; AS-2P: L-ascorbyl-2-phosphate; BBB: Blood-brain barrier; BDNF: Brain-derived, neurotrophic factor; CIS: Clinically isolated syndrome; CLOB: Clobetasol; CNPase: 2',3'-Cyclic-nucleotide 3'phosphodiesterase; CNS: Central nervous system; CSF: Cerebrospinal fluid; EAE: Experimental autoimmune encephalomyelitis; ER: Endoplasmatic reticulum; Erk1/2: Extracellular related-kinase 1 and 2; FGFR: Fibroblast growth factor receptor; G-actin: Globular actin; GAP43: Growth-associated protein 43; ICAM-1: Intracellular adhesion molecule-1; ILK: Integrin linked kinase; iNOS: Inducible nitric oxide synthase; IRAK1: Interleukin-1 receptorassociated kinase; LPC: Lysolecithin; MAG: Myelin associated glycoprotein; MAP: Microtubule-associated protein; MBP: Myelin basic protein; MS: Multiple sclerosis; mTOR: Mammalian target of rapamycin; MYRF: Myelin regulatory factor; NGF: Neurotrophin; NMO: Neuromyelitis optica; OPC: Oligodendroglial precursor cells; p38MAPK: p38 mitogen-activated protein kinase; PDE: Phosphodiesterase; PMS: Progressive multiple sclerosis; RGM: Repulsive guidance molecule; RIS: Radiologically isolated syndrome; RMS: Relapsing multiple sclerosis; SAE: Serious adverse event; SAH: Subarachnoid haemorrhage; SAPPalpha: Soluble N-terminal amyloid precursor protein alpha; SERM: Selective estrogen receptor modulator; Shh: Sonic hedgehog; Smo: G protein-coupled receptor Smoothened; TDP6: Tricyclic dimeric peptide 6; Tf4: Transcription factor 4; TrkB: Tropomyosin-related kinase B; Tß34: Thymosin beta-4
\end{abstract}

\section{Acknowledgements}

Not applicable.

\section{Authors' contributions}

All authors read, reviewed and approved the final manuscript. All authors equally contributed to the editing of the article. PG mainly contributed to the conception, literature search and writing of the sections Etazolate, Klotho, Smoothened (Smo), Myelin regulatory factor (MYRF), Miscellaneous other molecules as well as to the figure designing; MF to the conception, literature search and writing of the sections Thymosin- $\beta 4$, Hesperidin and hesperetin, Quercetin, Tricyclic-dimeric peptide-6 (TDP6) - BDNF and Repulsive guidance molecule a (RGMa); $\mathrm{WW}$ of the sections L-ascorbyl-2-phosphate (As-2P) and Nimodipine; PK of the sections MiR-146a and Miscellaneous other molecules; DK of the sections Introduction and Conclusion as well as conception, review and supplementation of the entire article. KR and HPH reviewed and edited the entire article and contribute to the conception and supplementation of the article.

\section{Funding}

None of the authors received funding for preparation of this manuscript Research on myelin repair in the laboratory of PK was supported by the French societies ARSEP and AFM, by the Deutsche Forschungsgemeinschaft (DFG; grants KU1934/2-1, KU1934/5-1), by the Stifterverband/ Novartisstiftung, by the Christiane and Claudia Hempel Foundation for clinical stem cell research, iBrain, Sanofi/Genzyme and Geneuro. The MS Center at the Department of Neurology in Düsseldorf is supported in part by the Walter and Ilse Rose Foundation and the James and Elisabeth Cloppenburg, Peek, and Cloppenburg Düsseldorf Stiftung.

\section{Availability of data and materials}

Data sharing is not applicable to this article as no datasets were generated.

\section{Ethics approval and consent to participate}

This manuscript does not involve the use of any animal or human data or tissues.

\section{Consent for publication}

Not applicable.

\section{Competing interests}

PG and PK performed consultancy work for GeNeuro. HPH received consultancy fees and fees for serving on steering or data monitoring committees and adboards from Bayer Healthcare, Biogen, GeNeuro, Genzyme, MedDay, Merck, Novartis, Celgene Receptos, Roche, Teva with approval by the Rector of Heinrich-Heine-University. DK received travel grants from GeNeuro and Merck, refund of congress participation fees from GeNeuro, Merck, Servier, consulting fees from Grifols, payment for lectures from Grifols and support for research projects from Teva. MF, WW and KR declare that they have no competing interests.

\section{Author details}

'Department of Neurology, Medical Faculty, Heinrich-Heine-University, Moorenstrasse 5, 40225 Düsseldorf, Germany. ${ }^{2}$ Department of Neurology, Medical University of Lublin, Lublin, Poland.

Received: 11 March 2019 Accepted: 14 May 2019

Published online: 08 July 2019

\section{References}

1. Abraham, C. R., Chen, C., Cuny, G. D., Glicksman, M. A., \& Zeldich, E. (2012). Small-molecule klotho enhancers as novel treatment of neurodegeneration. Future Medicinal Chemistry, 4(13), 1671-1679. https:// doi.org/10.4155/fmc.12.134.

2. Akkermann, R., Beyer, F., \& Küry, P. (2017). Heterogeneous populations of neural stem cells contribute to myelin repair. Neural Regeneration Research, 12(4), 509.

3. Amato, M. P., Hakiki, B., Goretti, B., Rossi, F., Stromillo, M. L., Giorgio, A., et al. (2012). Association of MRI metrics and cognitive impairment in radiologically isolated syndromes. Neurology, 78(5), 309-314. https://doi.org/ 10.1212/WNL.0b013e31824528c9.

4. Banerjee, P., Harada, H., Tassew, N. G., Charish, J., Goldschneider, D., Wallace, V. A., et al. (2016). Upsilon-secretase and LARG mediate distinct RGMa activities to control appropriate layer targeting within the optic tectum. Cell Death and Differentiation, 23(3), 442-453. https://doi.org/10. 1038/cdd.2015.111.

5. Baradaran, S., Hajizadeh Moghaddam, A., \& Ghasemi-Kasman, M. (2018). Hesperetin reduces myelin damage and ameliorates glial activation in Iysolecithin-induced focal demyelination model of rat optic chiasm. Life Sciences, 207, 471-479. https://doi.org/10.1016/j.lfs.2018.07.001.

6. Barratt, H. E., Budnick, H. C., Parra, R., Lolley, R. J., Perry, C. N., \& Nesic, O. (2016). Tamoxifen promotes differentiation of oligodendrocyte progenitors in vitro. Neuroscience, 319, 146-154. https://doi.org/10.1016/j.neuroscience. 2016.01.026.

7. Besler, H. T., Comoglu, S., \& Okcu, Z. (2002). Serum levels of antioxidant vitamins and lipid peroxidation in multiple sclerosis. Nutritional Neuroscience, 5(3), 215-220. https://doi.org/10.1080/10284150290029205.

8. Carvalho, F. B., Gutierres, J. M., Beckmann, D., Santos, R. P., Thome, G. R. Baldissarelli, J., et al. (2018). Quercetin treatment regulates the $\mathrm{Na}(+), \mathrm{K}(+$ )-ATPase activity, peripheral cholinergic enzymes, and oxidative stress in a rat model of demyelination. Nutrition Research, 55, 45-56. https://doi.org/10. 1016/j.nutres.2018.04.004.

9. Cellerino, A., Carroll, P., Thoenen, H., \& Barde, Y. A. (1997). Reduced size of retinal ganglion cell axons and hypomyelination in mice lacking brainderived neurotrophic factor. Molecular and Cellular Neurosciences, 9(5-6), 397-408. https://doi.org/10.1006/mcne.1997.0641.

10. Chang, A., Tourtellotte, W. W., Rudick, R., \& Trapp, B. D. (2002). Premyelinating oligodendrocytes in chronic lesions of multiple sclerosis. New England Journal of Medicine, 346(3), 165-173.

11. Chao, M. V. (2003). Neurotrophins and their receptors: A convergence point for many signalling pathways. Nature Reviews Neuroscience, 4(4), 299.

12. Chen, C. D., Sloane, J. A., Li, H., Aytan, N., Giannaris, E. L., Zeldich, E., et al. (2013). The antiaging protein klotho enhances oligodendrocyte maturation and myelination of the CNS. The Journal of Neuroscience, 33(5), 1927-1939. https:// doi.org/10.1523/JNEUROSCI.2080-12.2013.

13. Ciftci, O., Ozcan, C., Kamisli, O., Cetin, A., Basak, N., \& Aytac, B. (2015). Hesperidin, a citrus flavonoid, has the ameliorative effects against experimental autoimmune encephalomyelitis (EAE) in a C57BL/J6 mouse model. Neurochemical Research, 40(6), 1111-1120. https://doi.org/10.1007/s11064-015-1571-8. 
14. Del Giovane, A., \& Ragnini-Wilson, A. (2018). Targeting smoothened as a new frontier in the functional recovery of central nervous system demyelinating pathologies. International Journal of Molecular Sciences, 19(11). https://doi.org/10.3390/ijms19113677.

15. Demicheva, E., Cui, Y. F., Bardwell, P., Barghorn, S., Kron, M., Meyer, A. H., et al. (2015). Targeting repulsive guidance molecule a to promote regeneration and neuroprotection in multiple sclerosis. Cell Reports, 10(11), 1887-1898. https://doi.org/10.1016/j.celrep.2015.02.048.

16. Dolati, S., Marofi, F., Babaloo, Z., Aghebati-Maleki, L., Roshangar, L., Ahmadi, M., et al. (2018). Dysregulated network of miRNAs involved in the pathogenesis of multiple sclerosis. Biomedicine \& Pharmacotherapy, 104, 280-290. https://doi.org/10.1016/j.biopha.2018.05.050.

17. Duncan, G. J., Plemel, J. R., Assinck, P., Manesh, S. B., Muir, F. G. W., Hirata, R., et al. (2017). Myelin regulatory factor drives remyelination in multiple sclerosis. Acta Neuropathologica, 134(3), 403-422. https://doi.org/10.1007/s00401-017-1741-7.

18. Duncan, I. D., Radcliff, A. B., Heidari, M., Kidd, G., August, B. K., \& Wierenga, L. A. (2018). The adult oligodendrocyte can participate in remyelination. Proceedings of the National Academy of Sciences of the United States of America, 115(50), E1 1807-E11816. https://doi.org/10.1073/pnas.1808064115.

19. Emery, B., Agalliu, D., Cahoy, J. D., Watkins, T. A., Dugas, J. C., Mulinyawe, S. B. , et al. (2009). Myelin gene regulatory factor is a critical transcriptional regulator required for CNS myelination. Cell, 138(1), 172-185. https://doi.org/ 10.1016/j.cell.2009.04.031.

20. Falcão, A. M., van Bruggen, D., Marques, S., Meijer, M., Jäkel, S., Agirre, E., et al. (2018). Disease-specific oligodendrocyte lineage cells arise in multiple sclerosis. Nature Medicine, 24(12), 1837

21. Fancy, S. P., Chan, J. R., Baranzini, S. E., Franklin, R. J., \& Rowitch, D. H. (2011). Myelin regeneration: A recapitulation of development? Annual Review of Neuroscience, 34, 21-43. https://doi.org/10.1146/annurev-neuro061010-113629.

22. Fancy, S. P., Kotter, M. R., Harrington, E. P., Huang, J. K., Zhao, C., Rowitch, D. H., \& Franklin, R. J. (2010). Overcoming remyelination failure in multiple sclerosis and other myelin disorders. Experimental Neurology, 225(1), 18-23. https://doi.org/10.1016/j.expneurol.2009.12.020.

23. Fletcher, J. L., Wood, R. J., Nguyen, J., Norman, E. M. L., Jun, C. M. K., Prawdiuk, A. R., et al. (2018). Targeting TrkB with a brain-derived neurotrophic factor mimetic promotes myelin repair in the brain. The Journal of Neuroscience, 38(32), 7088-7099. https://doi.org/10.1523/ JNEUROSCI.0487-18.2018.

24. Fyffe-Maricich, S. L., Schott, A., Karl, M., Krasno, J., \& Miller, R. H. (2013). Signaling through ERK1/2 controls myelin thickness during myelin repair in the adult central nervous system. The Journal of Neuroscience, 33(47), $18402-$ 18408. https://doi.org/10.1523/JNEUROSCI.2381-13.2013.

25. Goldstein, A. L., Hannappel, E., \& Kleinman, H. K. (2005). Thymosin beta4: Actinsequestering protein moonlights to repair injured tissues. Trends in Molecular Medicine, 11(9), 421-429. https://doi.org/10.1016/j.molmed.2005.07.004.

26. Gonsette, R. E. (2008a). Neurodegeneration in multiple sclerosis: The role of oxidative stress and excitotoxicity. Journal of the Neurological Sciences, 274(1-2), 48-53. https://doi.org/10.1016/j.jns.2008.06.029.

27. Gonsette, R. E. (2008b). Oxidative stress and excitotoxicity: A therapeutic issue in multiple sclerosis? Multiple Sclerosis, 14(1), 22-34. https://doi.org/10. $1177 / 1352458507080111$

28. Gonzalez, G. A., Hofer, M. P., Syed, Y. A., Amaral, A. I., Rundle, J., Rahman, S., et al. (2016). Tamoxifen accelerates the repair of demyelinated lesions in the central nervous system. Scientific Reports, 6, 31599. https://doi.org/10.1038/ srep31599.

29. Grieb, P. (2014). Neuroprotective properties of citicoline: Facts, doubts and unresolved issues. CNS Drugs, 28(3), 185-193. https://doi.org/10. 1007/s40263-014-0144-8.

30. Grieb, P. (2015). Beneficial effects of exogenous CDP-choline (citicoline) in EAE. Brain, 138(Pt 11), e388. https://doi.org/10.1093/ brain/awv140.

31. Guo, Y.-e., Suo, N., Cui, X., Yuan, Q., \& Xie, X. (2018). Vitamin C promotes oligodendrocytes generation and remyelination. Glia, 66(7), 1302-1316

32. Haghmorad, D., Mahmoudi, M. B., Salehipour, Z., Jalayer, Z., Rastin, M., Kokhaei, P., \& Mahmoudi, M. (2017). Hesperidin ameliorates immunological outcome and reduces neuroinflammation in the mouse model of multiple sclerosis. Journal of Neuroimmunology, 302, 23-33.

33. Harada, K., Fujita, Y., Okuno, T., Tanabe, S., Koyama, Y., Mochizuki, H., \& Yamashita, T. (2018). Inhibition of RGMa alleviates symptoms in a rat model of neuromyelitis optica. Scientific Reports, 8(1), 34. https://doi.org/ 10.1038/s41598-017-18362-2.

34. Huang, H., Teng, P., Du, J., Meng, J., Hu, X., Tang, T., et al. (2018). Interactive repression of MYRF self-cleavage and activity in oligodendrocyte differentiation by TMEM98 protein. The Journal of Neuroscience, 38(46), 9829-9839. https://doi.org/10.1523/JNEUROSCl.0154-18.2018.

35. Hwang, S.-L., Shih, P.-H., \& Yen, G.-C. (2012). Neuroprotective effects of citrus flavonoids. Journal of Agricultural and Food Chemistry, 60(4), 877-885.

36. Ikram, M., Muhammad, T., Rehman, SU., Khan, A., Jo, MG., Ali, T., Kim, MO. (2019). Hesperetin Confers Neuroprotection by Regulating Nrf2/TLR4/NF-KB Signaling in an A $\beta$ Mouse Model. Mol Neurobiol. doi: https://doi.org/10. 1007/s12035-019-1512-7. [Epub ahead of print].

37. Ineichen, B. V., Kapitza, S., Bleul, C., Good, N., Plattner, P. S., Seyedsadr, M. S., et al. (2017). Nogo-A antibodies enhance axonal repair and remyelination in neuro-inflammatory and demyelinating pathology. Acta Neuropathologica, 134(3), 423-440. https://doi.org/10.1007/s00401-017-1745-3.

38. Ineichen, B. V., Plattner, P. S., Good, N., Martin, R., Linnebank, M., \& Schwab, M. E. (2017). Nogo-a antibodies for progressive multiple sclerosis. CNS Drugs, 31(3), 187-198. https://doi.org/10.1007/s40263-017-0407-2.

39. Ingwersen, J., De Santi, L., Wingerath, B., Graf, J., Koop, B., Schneider, R., et al. (2018). Nimodipine confers clinical improvement in two models of experimental autoimmune encephalomyelitis. Journal of Neurochemistry. https://doi.org/10.1111/jnc.14324.

40. Jäkel, S., Agirre, E., Falcão, A. M., Van Bruggen, D., Lee, K. W., Knuesel, l., et al. (2019). Altered human oligodendrocyte heterogeneity in multiple sclerosis. Nature, 566(7745), 543

41. Jones, K. R., Farinas, I., Backus, C., \& Reichardt, L. F. (1994). Targeted disruption of the BDNF gene perturbs brain and sensory neuron development but not motor neuron development. Cell, 76(6), 989-999.

42. Jurynczyk, M., \& Selmaj, K. (2010). Notch: A new player in MS mechanisms. Journal of Neuroimmunology, 218(1-2), 3-11. https://doi.org/10.1016/j. jneuroim.2009.08.010.

43. Kang, C. H., Choi, Y. H., Moon, S. K., Kim, W. J., \& Kim, G. Y. (2013). Quercetin inhibits lipopolysaccharide-induced nitric oxide production in BV2 microglial cells by suppressing the NF-kappaB pathway and activating the Nrf2dependent HO-1 pathway. International Immunopharmacology, 17(3), 808813. https://doi.org/10.1016/j.intimp.2013.09.009.

44. Kim, J., Hyun, J., Wang, S., Lee, C., Lee, J. W., Moon, E. Y., et al. (2017). Thymosin beta-4 regulates activation of hepatic stellate cells via hedgehog signaling. Scientific Reports, 7(1), 3815. https://doi.org/10.1038/s41598-017-03782-x.

45. Kitayama, M., Ueno, M., Itakura, T., \& Yamashita, T. (2011). Activated microglia inhibit axonal growth through RGMa. PLoS One, 6(9), e25234. https://doi. org/10.1371/journal.pone.0025234.

46. Koenning, M., Jackson, S., Hay, C. M., Faux, C., Kilpatrick, T. J., Willingham, M., \& Emery, B. (2012). Myelin gene regulatory factor is required for maintenance of myelin and mature oligodendrocyte identity in the adult CNS. The Journal of Neuroscience, 32(36), 12528-12542. https://doi.org/10. 1523/JNEUROSCI.1069-12.2012.

47. Kremer, D., Göttle, P., Hartung, H. P., \& Küry, P. (2016). Pushing forward: Remyelination as the new frontier in CNS diseases. Trends in Neurosciences, 39(4), 246-263. https://doi.org/10.1016/j.tins.2016.02.004.

48. Kremer, D., Schichel, T., Förster, M., Tzekova, N., Bernard, C., van der Valk, P., et al. (2013). Human endogenous retrovirus type W envelope protein inhibits oligodendroglial precursor cell differentiation. Annals of Neurology, 74(5), 721-732. https://doi.org/10.1002/ana.23970.

49. Kuhlmann, T., Lingfeld, G., Bitsch, A., Schuchardt, J., \& Brück, W. (2002). Acute axonal damage in multiple sclerosis is most extensive in early disease stages and decreases over time. Brain, 125(Pt 10), 2202-2212.

50. Kuhlmann, T., Miron, V., Cui, Q., Wegner, C., Antel, J., \& Brück, W. (2008). Differentiation block of oligodendroglial progenitor cells as a cause for remyelination failure in chronic multiple sclerosis. Brain, 131(Pt 7), 17491758. https://doi.org/10.1093/brain/awn096.

51. Kuro-o, M. (2010). Klotho. Pflügers Archiv, 459(2), 333-343. https://doi.org/10. 1007/s00424-009-0722-7.

52. Kuro-o, M., Matsumura, Y., Aizawa, H., Kawaguchi, H., Suga, T., Utsugi, T., et al. (1997). Mutation of the mouse klotho gene leads to a syndrome resembling ageing. Nature, 390(6655), 45-51. https://doi.org/10.1038/36285.

53. Kuroda, M., Muramatsu, R., Maedera, N., Koyama, Y., Hamaguchi, M., Fujimura, H., et al. (2017). Peripherally derived FGF21 promotes remyelination in the central nervous system. The Journal of Clinical Investigation, 127(9), 3496-3509. https://doi.org/10.1172/JCl94337. 
54. Lien, E. A., Wester, K., Lonning, P. E., Solheim, E., \& Ueland, P. M. (1991) Distribution of tamoxifen and metabolites into brain tissue and brain metastases in breast cancer patients. British Journal of Cancer, 63(4), 641645.

55. Liguori, M., Qualtieri, A., Tortorella, C., Direnzo, V., Bagala, A., Mastrapasqua, M., et al. (2014). Proteomic profiling in multiple sclerosis clinical courses reveals potential biomarkers of neurodegeneration. PLoS One, 9(8), e103984. https://doi.org/10.1371/journal.pone.0103984.

56. Llufriu-Daben, G., Carrete, A., Chierto, E., Mailleux, J., Camand, E., Simon, A., et al. (2018). Targeting demyelination via alpha-secretases promoting sAPPalpha release to enhance remyelination in central nervous system. Neurobiology of Disease, 109(Pt A), 11-24. https://doi.org/10.1016/j.nbd.2017. 09.008 .

57. Maccarrone, G., Nischwitz, S., Deininger, S. O., Hornung, J., Konig, F. B., Stadelmann, C., et al. (2017). MALDI imaging mass spectrometry analysis-a new approach for protein mapping in multiple sclerosis brain lesions. Journal of Chromatography. B, Analytical Technologies in the Biomedical and Life Sciences, 1047, 131-140. https://doi.org/10.1016/j.jchromb.2016.07.001.

58. Marcade, M., Bourdin, J., Loiseau, N., Peillon, H., Rayer, A., Drouin, D., et al. (2008). Etazolate, a neuroprotective drug linking GABA(a) receptor pharmacology to amyloid precursor protein processing. Journal of Neurochemistry, 106(1), 392-404. https://doi.org/10.1111/j.1471-4159.2008. 05396.x.

59. Marques, S., Zeisel, A., Codeluppi, S., van Bruggen, D., Falcão, A. M., Xiao, L., et al. (2016). Oligodendrocyte heterogeneity in the mouse juvenile and adult central nervous system. Science, 352(6291), 1326-1329.

60. Mehta, V., Parashar, A., \& Udayabanu, M. (2017). Quercetin prevents chronic unpredictable stress induced behavioral dysfunction in mice by alleviating hippocampal oxidative and inflammatory stress. Physiology \& Behavior, 171, 69-78. https://doi.org/10.1016/j.physbeh.2017.01.006.

61. Metz, L. M., Li, D. K. B., Traboulsee, A. L., Duquette, P., Eliasziw, M., Cerchiaro, G., et al. (2017). Trial of minocycline in a clinically isolated syndrome of multiple sclerosis. New England Journal of Medicine, 376(22), 2122-2133.

62. Moosavi, F., Hosseini, R., Saso, L., \& Firuzi, O. (2016). Modulation of neurotrophic signaling pathways by polyphenols. Drug Design, Development and Therapy, 10, 23-42. https://doi.org/10.2147/DDDT.S96936.

63. Muramatsu, R., Kubo, T., Mori, M., Nakamura, Y., Fujita, Y., Akutsu, T., et al. (2011). RGMa modulates T cell responses and is involved in autoimmune encephalomyelitis. Nature Medicine, 17(4), 488-494. https://doi.org/10.1038/ $\mathrm{nm} .2321$.

64. Naeimi, R., Baradaran, S., Ashrafpour, M., Moghadamnia, A. A., \& GhasemiKasman, M. (2018). Querectin improves myelin repair of optic chiasm in lyolecithin-induced focal demyelination model. Biomedicine \& Pharmacotherapy, 101, 485-493. https://doi.org/10.1016/j.biopha.2018.02.125.

65. Najm, F. J., Madhavan, M., Zaremba, A., Shick, E., Karl, R. T., Factor, D. C., et al. (2015). Drug-based modulation of endogenous stem cells promotes functional remyelination in vivo. Nature, 522(7555), 216-220. https://doi.org/ 10.1038/nature14335

66. Nakajima, K., Niisato, N., \& Marunaka, Y. (2011). Quercetin stimulates NGFinduced neurite outgrowth in $\mathrm{PC} 12$ cells via activation of $\mathrm{Na}(+) / \mathrm{K}(+) / 2 \mathrm{Cl}(-)$ cotransporter. Cellular Physiology and Biochemistry, 28(1), 147-156. https:// doi.org/10.1159/000331723.

67. O'Leary, P. D., \& Hughes, R. A. (2003). Design of potent peptide mimetics of brain-derived neurotrophic factor. Journal of Biological Chemistry, 278(28), 25738-25744

68. Ontaneda, D., Cohen, J. A., \& Amato, M. P. (2017). Clinical outcome measures for progressive MS trials. Multiple Sclerosis, 23(12), 1627-1635 https://doi.org/10.1177/1352458517729465

69. Osorio-Querejeta, I., Alberro, A., Munoz-Culla, M., Mager, I., \& Otaegui, D. (2018). Therapeutic potential of extracellular vesicles for demyelinating diseases; challenges and opportunities. Frontiers in Molecular Neuroscience, 11, 434. https://doi.org/10.3389/fnmol.2018.00434.

70. Pardridge, W. M. (2005). The blood-brain barrier: Bottleneck in brain drug development. NeuroRX, 2(1), 3-14. https://doi.org/10.1602/neurorx.2.1.3.

71. Porcu, G., Serone, E., De Nardis, V., Di Giandomenico, D., Lucisano, G., Scardapane, M., et al. (2015). Clobetasol and Halcinonide act as smoothened agonists to promote myelin gene expression and RxRgamma receptor activation. PLoS One, 10(12), e0144550. https://doi.org/10.1371/journal.pone.0144550.

72. Quarles, L. D. (2012a). Role of FGF23 in vitamin D and phosphate metabolism: Implications in chronic kidney disease. Experimental Cell Research, 318(9), 1040-1048. https://doi.org/10.1016/j.yexcr.2012.02.027.
73. Quarles, L. D. (2012b). Skeletal secretion of FGF-23 regulates phosphate and vitamin D metabolism. Nature Reviews. Endocrinology, 8(5), 276-286. https://doi.org/10.1038/nrendo.2011.218.

74. Rao, A. M., Hatcher, J. F., \& Dempsey, R. J. (1999). CDP-choline: Neuroprotection in transient forebrain ischemia of gerbils. Journal of Neuroscience Research, 58(5), 697-705.

75. Reich, D. S., Lucchinetti, C. F., \& Calabresi, P. A. (2018). Multiple sclerosis. The New England Journal of Medicine, 378(2), 169-180. https://doi.org/10.1056/NEJMra1401483.

76. Rejdak, K., Rejdak, R., Sieklucka-Dziuba, M., Stelmasiak, Z., \& Grieb, P. (2001). The effects of citicoline and/or MK-801 on survival, neurological and behavioral outcome of mice exposed to transient hyperglycemia and oligemic hypoxia. European Neuropsychopharmacology, 11(5), 333-341.

77. Ren, H., Hao, J., Liu, T., Zhang, D., Lv, H., Song, E., \& Zhu, C. (2016). Hesperetin suppresses inflammatory responses in lipopolysaccharideinduced RAW 264.7 cells via the inhibition of NF-kappaB and activation of Nrf2/HO-1 pathways. Inflammation, 39(3), 964-973. https://doi.org/10.1007/s10753-016-0311-9.

78. Sanders, M. C., Goldstein, A. L., \& Wang, Y. L. (1992). Thymosin beta 4 (Fx peptide) is a potent regulator of actin polymerization in living cells. Proceedings of the National Academy of Sciences of the United States of America, 89(10), 4678-4682.

79. Santra, M., Chopp, M., Zhang, Z. G., Lu, M., Santra, S., Nalani, A., et al. (2012). Thymosin beta 4 mediates oligodendrocyte differentiation by upregulating p38 MAPK. Glia, 60(12), 1826-1838. https://doi.org/10.1002/ glia.22400.

80. Santra, M., Zhang, Z. G., Yang, J., Santra, S., Santra, S., Chopp, M., \& Morris, D. C. (2014). Thymosin beta4 up-regulation of microRNA-146a promotes oligodendrocyte differentiation and suppression of the toll-like proinflammatory pathway. The Journal of Biological Chemistry, 289(28), 19508-19518. https://doi.org/10.1074/jbc.M113.529966.

81. Schampel, A., Volovitch, O., Koeniger, T., Scholz, C. J., Jorg, S., Linker, R. A., et al. (2017). Nimodipine fosters remyelination in a mouse model of multiple sclerosis and induces microglia-specific apoptosis. Proceedings of the National Academy of Sciences of the United States of America, 114(16), E3295E3304. https://doi.org/10.1073/pnas.1620052114.

82. Schwab, M. E., \& Strittmatter, S. M. (2014). Nogo limits neural plasticity and recovery from injury. Current Opinion in Neurobiology, 27, 53-60. https://doi. org/10.1016/j.conb.2014.02.011.

83. Siebold, C., Yamashita, T., Monnier, P. P., Mueller, B. K., \& Pasterkamp, R. J. (2017). RGMs: Structural insights, molecular regulation, and downstream signaling. Trends in Cell Biology, 27(5), 365-378. https://doi.org/10.1016/j.tcb. 2016.11.009.

84. Singh, R. P., Sharad, S., \& Kapur, S. (2004). Free radicals and oxidative stress in neurodegenerative diseases: Relevance of dietary antioxidants. Journal, Indian Academy of Clinical Medicine, 5(3), 218-225.

85. Skripuletz, T., Linker, R. A., \& Stangel, M. (2015). The choline pathway as a strategy to promote central nervous system (CNS) remyelination. Neural Regeneration Research, 10(9), 1369-1370. https://doi.org/10.4103/1673-5374. 165498.

86. Skripuletz, T., Manzel, A., Gropengiesser, K., Schafer, N., Gudi, V., Singh, V., et al. (2015). Pivotal role of choline metabolites in remyelination. Brain, 138(Pt 2), 398-413. https://doi.org/10.1093/brain/awu358.

87. Sormani, M. P., \& Pardini, M. (2017). Assessing repair in multiple sclerosis: Outcomes for phase II clinical trials. Neurotherapeutics, 14(4), 924-933. https://doi.org/10.1007/s13311-017-0558-3.

88. Suganthy, N., Devi, K. P., Nabavi, S. F., Braidy, N., \& Nabavi, S. M. (2016). Bioactive effects of quercetin in the central nervous system: Focusing on the mechanisms of actions. Biomedicine \& Pharmacotherapy, 84, 892-908. https://doi.org/10.1016/j.biopha.2016.10.011.

89. Tanabe, S., Fujita, Y., Ikuma, K., \& Yamashita, T. (2018). Inhibiting repulsive guidance molecule-a suppresses secondary progression in mouse models of multiple sclerosis. Cell Death \& Disease, 9(11), 1061. https://doi.org/10. 1038/s41419-018-1118-4.

90. Tavazzi, B., Batocchi, A. P., Amorini, A. M., Nociti, V., D'Urso, S., Longo, S., et al (2011). Serum metabolic profile in multiple sclerosis patients. Multiple Sclerosis International, 2011, 167156. https://doi.org/10.1155/2011/167156.

91. Thompson, A. J., Baranzini, S. E., Geurts, J., Hemmer, B., \& Ciccarelli, O. (2018). Multiple sclerosis. Lancet, 391(10130), 1622-1636. https://doi.org/10.1016/ S0140-6736(18)30481-1. 
92. Torbus-Paluszczak, M., Bartman, W., \& Adamczyk-Sowa, M. (2018). Klotho protein in neurodegenerative disorders. Neurological Sciences, 39(10), 16771682. https://doi.org/10.1007/s10072-018-3496-X.

93. Uchida, S., Yamada, S., Nagai, K., Deguchi, Y., \& Kimura, R. (1997). Brain pharmacokinetics and in vivo receptor binding of 1,4-dihydropyridine calcium channel antagonists. Life Sciences, 61(21), 2083-2090.

94. Viganò, F., Möbius, W., Götz, M., \& Dimou, L. (2013). Transplantation reveals regional differences in oligodendrocyte differentiation in the adult brain. Nature Neuroscience, 16(10), 1370.

95. Wang, L. C., \& Almazan, G. (2016). Role of sonic hedgehog signaling in oligodendrocyte differentiation. Neurochemical Research, 41(12), 3289-3299. https://doi.org/10.1007/s11064-016-2061-3.

96. Wang, P., Myers, J. G., Wu, P., Cheewatrakoolpong, B., Egan, R. W., \& Billah, M. M. (1997). Expression, purification, and characterization of human CAMPspecific phosphodiesterase (PDE4) subtypes A, B, C, and D. Biochemical and Biophysical Research Communications, 234(2), 320-324. https://doi.org/10. 1006/bbrc.1997.6636.

97. Williams, M., \& Jarvis, M. F. (1988). Adenosine antagonists as potential therapeutic agents. Pharmacology, Biochemistry, and Behavior, 29(2), 433-441.

98. Wong, A. W., Giuffrida, L., Wood, R., Peckham, H., Gonsalvez, D., Murray, S. S., et al. (2014). TDP6, a brain-derived neurotrophic factor-based trkB peptide mimetic, promotes oligodendrocyte myelination. Molecular and Cellular Neuroscience, 63, 132-140. https://doi.org/10.1016/j.mcn.2014.10.002.

99. Xiao, J., Ferner, A. H., Wong, A. W., Denham, M., Kilpatrick, T. J., \& Murray, S. S. (2012). Extracellular signal-regulated kinase $1 / 2$ signaling promotes oligodendrocyte myelination in vitro. Journal of Neurochemistry, 122(6), 1167-1180. https://doi.org/10.1111/j.1471-4159.2012.07871.x.

100. Xiao, J., Wong, A. W., Willingham, M. M., van den Buuse, M., Kilpatrick, T. J., \& Murray, S. S. (2010). Brain-derived neurotrophic factor promotes central nervous system myelination via a direct effect upon oligodendrocytes. Neurosignals, 18(3), 186-202. https://doi.org/10.1159/000323170.

101. Yang, Y., Bai, L., Li, X., Xiong, J., Xu, P., Guo, C., \& Xue, M. (2014). Transport of active flavonoids, based on cytotoxicity and lipophilicity: An evaluation using the blood-brain barrier cell and Caco-2 cell models. Toxicology In Vitro, 28(3), 388-396. https://doi.org/10.1016/j.tiv.2013.12.002.

102. Yao, X., Su, T., \& Verkman, A. S. (2016). Clobetasol promotes remyelination in a mouse model of neuromyelitis optica. Acta Neuropathologica Communications, 4(1), 42. https://doi.org/10.1186/s40478-016-0309-4.

103. Yeung, M. S. Y., Djelloul, M., Steiner, E., Bernard, S., Salehpour, M., Possnert, G., et al. (2019). Dynamics of oligodendrocyte generation in multiple sclerosis. Nature, 566(7745), 538-542. https://doi.org/10.1038/s41586-018-0842-3.

104. Ying, Y., \& Tao, Q. (2009). Epigenetic disruption of the WNT/beta-catenin signaling pathway in human cancers. Epigenetics, 4(5), 307-312.

105. Youdim, K. A., Dobbie, M. S., Kuhnle, G., Proteggente, A. R., Abbott, N. J., \& Rice-Evans, C. (2003). Interaction between flavonoids and the blood-brain barrier: In vitro studies. Journal of Neurochemistry, 85(1), 180-192.

106. Yu, X., Cheng, G., Zhang, L., Zhang, Y., Wang, Q., Zhao, M., et al. (2018). NPhenylquinazolin-2-amine Yhhu4952 as a novel promotor for oligodendrocyte differentiation and myelination. Scientific Reports, 8(1) 14040. https://doi.org/10.1038/s41598-018-32326-0.

107. Zhang, J., Zhang, Z. G., Li, Y., Lu, M., Zhang, Y., Elias, S. B., \& Chopp, M. (2016). Thymosin beta4 promotes oligodendrogenesis in the demyelinating central nervous system. Neurobiology of Disease, 88, 85-95. https://doi.org/10.1016/j. nbd.2016.01.010.

108. Zhang, J., Zhang, Z. G., Lu, M., Wang, X., Shang, X., Elias, S. B., \& Chopp, M. (2017). MiR-146a promotes remyelination in a cuprizone model of demyelinating injury. Neuroscience, 348, 252-263. https://doi.org/10.1016/j. neuroscience.2017.02.029.

109. Zhang, J., Zhang, Z. G., Morris, D., Li, Y., Roberts, C., Elias, S. B., \& Chopp, M. (2009). Neurological functional recovery after thymosin beta4 treatment in mice with experimental auto encephalomyelitis. Neuroscience, 164(4), 18871893. https://doi.org/10.1016/j.neuroscience.2009.09.054.

110. Zhang, Y., Yi, B., Ma, J., Zhang, L., Zhang, H., Yang, Y., \& Dai, Y. (2015). Quercetin promotes neuronal and behavioral recovery by suppressing inflammatory response and apoptosis in a rat model of intracerebral hemorrhage. Neurochemical Research, 40(1), 195-203.

111. Zhou, T., Huang, Y. X., Song, J. W., \& Ma, Q. M. (2015). Thymosin beta4 inhibits microglia activation through microRNA 146a in neonatal rats following hypoxia injury. Neuroreport, 26(17), 1032-1038. https://doi.org/10. 1097/WNR.0000000000000463.

\section{Publisher's Note}

Springer Nature remains neutral with regard to jurisdictional claims in published maps and institutional affiliations.
Ready to submit your research? Choose BMC and benefit from:

- fast, convenient online submission

- thorough peer review by experienced researchers in your field

- rapid publication on acceptance

- support for research data, including large and complex data types

- gold Open Access which fosters wider collaboration and increased citations

- maximum visibility for your research: over $100 \mathrm{M}$ website views per year

At BMC, research is always in progress.

Learn more biomedcentral.com/submissions 